\title{
The Third-year Vet Med Students' English Course Content and Learning Outcomes: Causes of Poor Performance
}

\author{
Larice Toko Lumanda \\ Department of English Letters and Civilization, University of Kinshasa, Kinshasa, Democratic Republic of Congo \\ Email address: \\ lumanda08@gmail.com \\ To cite this article: \\ Larice Toko Lumanda. The Third-year Vet Med Students' English Course Content and Learning Outcomes: Causes of Poor Performance. \\ International Journal of Language and Linguistics. Vol. 7, No. 5, 2019, pp. 230-234. doi: 10.11648/j.ij11.20190705.17
}

Received: August 17, 2019; Accepted: September 4, 2019; Published: September 20, 2019

\begin{abstract}
The Third-Year Vet Med Students at the University of Kinshasa have been learning English for three years. Unfortunately, they are not able to speak, listen, read and write English. This fact needs and an investigation in order to find out the causes of this phenomenon. The investigation can involve many aspects such as the teaching methods, teaching materials, the course content, the students' background, learning outcomes, etc., but this article tackles only the course content and learning outcomes. This paper aims at examining the course content and the learning outcomes in order to detect the causes of the Third-Year Vet Med students' poor performance in English. To reach this aim, both the course content and learning outcomes are examined on the basis of Syllabus Review Method. The course content is examined in order to make sure if it has all important sections such as course title, course description, learning outcomes, course syllabus, learning activities, Assessment types, required and recommended readings, and feedback for evaluation since these sections have a considerable impact on the students' performance. Moreover, the learning outcomes are examined in order to check whether they are clearly stated and measurable. When learning outcomes are clearly stated and measurable, both lecturer and students work together so as to achieve them at the completion of the course. The article starts by literature review of course content and learning outcomes; thereafter it presents the course content and learning outcomes mentioned in the Third-Year Vet Med Students' course handout. Next, it discusses the course content and learning outcomes with respect to recommendations proposed by the Course Planning Service and literature review. This discussion has led to the conclusion that the Third-Year Vet Med Students' poor performance is due to the poor course content and lack of clear and measurable learning outcomes. Therefore, it is suggested to conduct a scientific research about the Vet Med Students' needs in order to design appropriate course content with clear and measurable learning outcomes on the basis of Communicative Learning Principles.
\end{abstract}

Keywords: Vet Med Students, Learning Outcomes, Course Content, Causes, Poor Performance, Communicative Learning Principles

\section{Introduction}

Poor performance ascertained from the Third-Year Vet Med Students at the University of Kinshasa has led to the investigation into causes of this poor performance. The causes of poor performance can be related to either the students or the lecturer as Cascio [17] argues that "some reasons for poor performance are specific to the students and not related to external factors. For example, a learning disability is student-centered and may create an obstacle to reaching certain academic standards.... Teachers play a significant role in student performance and also can be responsible for poor student performance". To discover these causes, many aspects such as teaching methods, students' background knowledge, course content, learning outcomes, etc. can be examined. This article tackles only the course content and learning outcomes before other researches are conducted about other aspects. Therefore, this article aims at examining the Third-Year Vet Med Students' course content and learning outcomes in order to point out the causes of this poor performance in English. To reach this aim, the course content and learning outcomes are analyzed on the basis of the Review Syllabus Method since the course content reflects knowledge that will be transmitted from the lecturer to the students. It is from this knowledge that the learning outcomes are formulated. Parkes and Harris quoted by the Center for 
Urban Education [18] confirm that "syllabi area key feature of every academic course, documents that serve multiple purposes. Most often, syllabi are seen as contracts between students and the instructor and as records of what courses cover and how student outcomes and performance are evaluated for accountability purposes". The Review Syllabus Method is used in order to examine deeply each point in the course outline in order to see how much each point affects the students' performance. Furthermore, the learning outcomes are also examined deeply so as to get their clarity and effectiveness in achieving the expected students' performance. The deep analysis of both course content and learning outcomes through discussion has led to the results of this investigation.

As far as sections are concerned, this article has five main sections. The first part is the introduction in which research problem, aim, research method, and parts of this article are stated. The second section deals with review of literature about course content and learning outcome. Concerning the course content, the section discusses 8 main components of course content selected from the Course Planning Service. Thereafter, the section reminds the objectives definition and domains. The third section presents the course content and learning outcomes as mentioned in the course handout. The fourth part examines both the course content and learning outcomes. The last part draws a conclusion from the discussion and enumerates the causes of the Third-Year Vet Med Students, and it proposes some suggestions.

\section{Course Content and Learning Outcomes}

\subsection{Course Content}

Among the components of course content proposed by The Course Planning Service [5] the following are selected.

1. English title

2. Course description

3. Learning outcomes

4. Course syllabus

5. Course components (Learning activities)

6. Assessment type

7. Required and recommended readings

8. Feedback for evaluation

These components are very important since they have a considerable impact on the teaching/learning processes and students' performance. In the following line, each of these components is discussed so as to show its value in teaching/learning processes and students' performance.

\subsubsection{Course Title}

On the one hand, Spoor and Lehmiller [13] write "It would make intuitive sense that different titles might be perceived differently by students; however, research has yet to address whether and how course title affects perception of WGS course".

On the other hand, Flaherty and others [7] argue that "our research leads us to conclude that course titles may influence student learning in various ways".

Each course should be distinguished from others by a specific terminology that learners have to know. The course title influences both the syllabus design and learners' learning interest. Therefore, the lecturer has to write it correctly.

\subsubsection{Course Description}

A course description gives students a general view about what they are supposed to know and how much the course matches their needs and expectations. It also provides students with whatever should be done in order to reach the learning outcomes. Academic Handbook [1] specifies it in this way:

a description of the objectives and content of the course, which shall include a statement of what is expected of the student by way of preparation, tests, exercises, essays, laboratory reports, etc. (hereafter called ässignments)', and any specific requirements for attendance and participation.

The teaching/learning value of course description is that it helps both lecturer and students focus on what is important along the teaching/learning processes. It also allows them to make good use of time.

\subsubsection{Learning Outcomes}

Learning outcomes are what the students are able to do or perform at the completion of the course. They must be stated clearly by the lecturer i.e. they must be stated with measurable verbs. Learning outcomes are a target for both lecturer and students in the sense that they work together in order to attain a good performance. Cedefop [2] states that "learning outcomes statements help to clarify programme and qualifications intentions and make it easier for those involved - learners, parents, teachers or assessors - to work towards these expectations".

\subsubsection{Course Syllabus}

This section outlines, in a clear way, the main topics of the course to be learned by students. The topics should be outlined in a logical way. That is, the preceding topic should be the foundation of the following one so as to facilitate the students' learning. Furthermore, these topics must be selected on the basis of the learning outcomes.

\subsubsection{Course Components (Learning Activities)}

Learning activities must be well planned in order to move effectively to the achievement of the learning outcomes. Learning activities should be considered as opportunities which are given to students to practice what they have learned. This is the reason why learning activities are performed in the classroom and in the real settings. CELT [3] argues that "there are a wide range of activities used both inside and outside the classroom that promote active learning". When learning activities are designed on the basis of learning outcomes, students reach easily a good performance because students do or perform regularly what is expected from them at the completion of the course. 


\subsubsection{Assessment Type}

Students must be assessed before, during, and after the lectures. When they are assessed before the lecture, this assessment is called diagnostic assessment. Brown and Knight quoted by Surgenor [15] state that "diagnostic enables grading and degree classification". Diagnostic Assessment reveals what students know about the course, the students' abilities and skills before they start learning. This type of assessment is important since it gives the lecturer the real view on his/her students' prerequisites which must be considered in the course design. When students are assessed during the lectures, this type of assessment is known as Formative Assessment. Formative assessment deals with students' feedback during lectures. Huston and Thompson [9] write "for some time formative assessment with its emphasis on feedback to students was promoted as better practice than traditional summative assessment". Formative assessment reveals the students' progress, stagnancy or regress. The assessment that comes at the end of the lecture is referred to as Summative Assessment. It judges students' success or failure in attributing each student grades that confirm the success or failure. Stephen Chappuis and Jan Chappuis [4] argue that "to begin, let's look at summative assessment. In general, its results are used to make some sort of judgment, such as to determine what grade a student will receive on a classroom assignment, measure program effectiveness, or determine whether a school has made adequate yearly progress".

\subsubsection{Required and Recommended Reading}

One of the language skills is reading skill. Students must develop reading skills because their education is based on reading and research. Therefore, one of the lecturer's tasks is to lead students to systematic reading practices. That is why every course should contain required and recommended reading so as to make students read for better understanding of the course and enlargement of their knowledge. Hermida cited by O'Connor [11].

When teachers design an aligned course that places academic reading at the forefront of the course, where the selected class activities encourage students to use higherorder cognitive skills to construct meaning from academic texts, and teachers implement assessment tools aimed at evaluating whether students use such skills to read academic texts, the result is that students tend to take a deep approach to reading and learning.

Course content must tell students required books and recommended ones. That is to say at the beginning of the course, students should know the books they have to read for understanding the course and the books that contribute to enlarge their knowledge in the field.

\subsubsection{Feedback for Evaluation}

At the completion of course, the lecturer is expected to get a feedback about the students' learning so as to see whether the students are able to do or perform what was/were stated in the learning outcomes. In the case the students can perform as it was expected, the lecturer can maintain the course content and the learning outcomes. In the case of students' poor performance, the lecturer has to revisit the course content and the learning outcomes. Desheng and Varghese [6] define evaluation as "the comparison of actual (project) impacts against the agreed strategic plans. It looks at the original objectives, at what was accomplished, and how it was accomplished". This is to say that course content should have a section relating to the feedback for evaluation.

\subsection{Objectives Definition}

In teaching, the term objectives can be referred to as aims or goals, learning objectives, and learning outcomes. Popenici and Millar [12] clarify these terms as follows:

Aims or goals in teaching and learning are broad sentences reflecting general intentions and desired outcomes of an institution, program or course.

Learning objectives refer to teachers' intentions for learners, such as what students will be taught during the course or program.

Learning outcomes are statements of what a student will be able to do or demonstrate at the completion of a certain sequence of learning (course, program).

In the case of this paper, aims or goals are the desire that the Veterinary Medicine Department has with regards to the students' education. The students in Veterinary Medicine Department are expected to speak, listen, read, and write English since this language is of the paramount importance in the field of veterinary medicine.

The lecturer has two important tasks viz designing a syllabus or an English course handout and stating clear and measurable learning outcomes. The decision about what should be taught to the Third-Year Vet Med Students must be based on the goal stated by the Veterinary Department and on what these students are expected to perform at the completion of the course. Harden [8] says that "learning outcomes are broad statements of what is achieved and assessed at the end of a course of study".

Learning outcomes should not be stated with verbs related to immeasurable actions as Surgenor [14] argues that "learning outcomes should therefore be expressed using verbs that specify exactly what the student will be able to do to demonstrate their mastery of the skills or materials".

\subsection{Objectives Domains}

Generally, objectives are categorized in three: Cognitive Domain, Psychomotor Domain, and Affective Domain. These three domains are explained by Yousefkhani [16] as follows:

The Cognitive Domain receiving the most attention in instructional programs includes objectives related to information or knowledge, naming, solving, predicting and other intellectual aspects of learning.

The second category for grouping instructional objectives encompasses the skills requiring the use and coordination of skeletal muscles, as in the physical activities of performing manipulating and constructing 
The third category of instructional involves objecting concerning attitudes, appreciations, values and emotion such as enjoying, conserving and respecting.

As far as the Cognitive Domain is concerned, the lecturer is supposed to design a course which should provide students with appropriate knowledge of technical words, oral expressions, tips for reading, tips for listening, and tips for writing mainly taking notes, summarizing texts, writing a veterinary medicine report, etc.

The Psychomotor Domain requires the lecturer to plan sufficient activities such as articulating English sounds i.e. asking students to use oral expressions, reading systematically according to the tips they have learnt, debating, holding discussions in the classrooms, etc.

Concerning the Affective Domain, the lecturer is expected to put students in context that allows them to enjoy the practice of English. That is to say, students are excited when they are in the setting where they can practice English by using expressions or tips they have learnt in the classroom.

\section{The Third-Year Vet Med Students' Course Content and Course Objectives}

\subsection{The Third-Year Vet Med Students' Course Content}

This section presents the course outline so as to have an idea about what the Third-Year Students learn in the English course and what they are expected to do or perform at the completion of the course. The first concern in this section is to check whether the course content fits the course content requirements and whether they are well-presented or not. The second concern is to examine how the learning outcomes are stated. In other words, this section examines the course content and the learning outcomes in order to detect the causes of the students' poor performance. Here below are the course outline and course outcomes as presented in the Third-year handout [10].

\subsection{Course Objectives}

Here below are the course outcomes:

i. To help third year students develop the four language skills, which are listening, reading, speaking, and writing.

ii. To allow students understand some of the verbs, rules and tenses used in English.

iii. To help students understand how to care about animals and breeding.

\section{Discussion}

The Course content of this English course lacks five important sections which have a considerable impact on the students' performance. It is clear that in this course content the following parts are missing: course title, course description, learning activities, required and recommended readings, and feedback for evaluation. Hence, the Third-Year Vet Med Students do not know exactly the course they take. Is it English, Technical English, Business English or what? Furthermore, no description of the course is given to the Third-Year Vet Med Students. This means that they do not know exactly what the course is about. In spite of missing description of the course, no learning activity is planned for these students. It is a proof that opportunities to use the English language are not given to these students. No required and recommended readings are prepared for the Third-Year Vet Med students. This fact reveals that these students cannot develop reading skills and as consequence, they cannot conduct any scientific research in English. To finish with the course content, one can notice that this course is not evaluated so as to bring modification or change in case there is some aspects to be improved or to maintain in case it works successfully. The danger is that the coming generation will have the same course content.

Now, let us examine the course objectives stated in the Third-Year Vet Med Students' handout. First of all, these course objectives are actually the learning outcomes that the lecturer has stated. The first impression one has is that the English Course taught to the Third-Year Vet Med Students has no learning outcomes. From this impression, it is clear that Vet Med Students are expected to do nothing at the completion of the course. This fact is proved when one examines deeply each of these course objectives. As far as the first objective is concerned, there is confusion between goals and learning outcomes. Goals are what the department expects from the students whereas learning outcomes are a change caused by the learning that occurs in the students at the completion of the course. In other words, learning outcomes are what the students can do or perform at the completion of the course. In the first course objective there two verbs namely help and develop. It is well known that learning outcomes should be measurable. These two verbs are not measurable i.e. there is no way to check whether the students have reached a good achievement. This first objective mentioned the four language skills (speaking, listening, reading, and writing). In the course outline, one can notice five texts which students can read and some notions of English greeting. This is to say that only one reading skill can be developed not the other languages skills because no activity is planned for speaking, listening, and writing. The notions of English greeting are not sufficient to develop speaking skills at the level of the third-year of undergraduate.

The second course objective, as the first one, has two verbs (allow and understand) whose actions are immeasurable. The focus in the second course objective is on verbs, rules, and tenses. That is, the Third-Year Students are supposed to understand verbs, rules, and tenses instead of using them. This course objective shows clearly that these Vet Med Students are not expected to practice English communicatively. The last course objective has also two verbs (help and understand). The focus is how to care about animals and breeding. This cannot be the learning outcome in teaching English. Instead, English expressions about caring animals and breeding should be 
taught. As it is already said above, this course objective cannot be measurable. Therefore, the Third-Year Students are taught without specific learning outcomes.

\section{Conclusion}

This article has been investigating - on the basis of course content and learning outcomes - into the causes of poor performance ascertained to the Third-Year Vet Med Students at the University of Kinshasa. The discussion has shown that course content lacks the course title, course description, course activities, required and recommended reading, and feedback for evaluation. This fact has revealed that the ThirdYear Vet Med Students are deprived from

i. having a clear idea about the course,

ii. learning activities which could give them opportunities to practice language,

iii. reading which could enlarge their knowledge, and

iv. any possible improvement.

Concerning learning outcomes, it has been noticed that in reality there are not learning outcomes since those pretended to be learning outcomes are not measurable.

In conclusion, the Third-Year Vet Med Students' poor performance is due to the poverty of the course. That is to say the course is not designed appropriately. To put it clear, the content of the course cannot enable these students reach an academic performance it lacks the appropriate learning activities which could develop in these students the four language skills. This is proved by the fact that no clear learning outcome is stated. The Third-Year Students do not know what they learn, why they it, and how to apply it.

Considering these two causes (poor course content and lack of clear learning outcomes) this article suggests the following:

i. to conduct a research about the students' needs so as to design an appropriate course content by including all important parts,

ii. to state clearly realistic learning outcomes based on communicative Learning Principles.

\section{References}

[1] Academic Handbook (2013) Course Outlines: Course Outlines (Syllabi) For Undergraduate Courses. Online.

[2] Cedefop. (2017). Defining, writing and applying learning outcomes: a European handbook. Luxembourg: Publications Office. http://dx.doi.org/10.2801/566770.

[3] CELT (2010). Classroom Learning Activities. Online.
[4] Chappuis, S. And Chappuis, J. (2008:14). The Best Value in Formative Assessment. Portland: Oregon.

[5] Course Planning Service. (2014). Course Outline Template. Online.

[6] Desheng, C. And Varghese, A. (2013). Testing and Evaluation of Language Skills in "OSR Journal of Research \& Method in Education”. Vol. 1. Issue 2. pp. 31-33 online.

[7] Flaherty, J. et. al. (2017). Words Matter: The Impact of "Catchy" vs Conventional Course Titles on Student Interest in "The Canadian Journal for the Scholarship of Teaching and Learning”, Vol. 8, Iss. 1, Art. 4.

[8] Harden, R. M. (2002). Learning outcomes and instructional objectives: is there a difference? in "Medical Teacher" Vol. 24, No. 2. pp. 151-155. Dundee: Centre for Medical Education, University of Dundee.

[9] Houston, D. And Thompson, J. N. (2017). "Blending Formative and Summative Assessment in a Capstone Subject: 'It's not your tools, it's how you use them" in Journal of University Teaching \& Learning Practice. vol. 14 Issue 3/2 pp. 113.

[10] Mumbembe, L. (2018-2019). English III For Third Year Undergraduate Veterinarian Students. Unpublished Course Notes. Kinshasa: UNIKIN.

[11] O'Connor, J. J. (2011). Make student reading interesting: An analysis of student reading in two courses in "Journal of Instructional Pedagogies" Retrieved December 19, 2011, from http://www.aabri.com/manuscripts/09150.pdf.

[12] Popenici, S. And Millar, V. (2015). Writing Learning Outcomes: A practical Guide for Academics. Melbourne: The University of Melbourne.

[13] Spoor, J. R. And Lehmiller, J. J. (2014). "The Impact of Course Title and Student Perceptions and Interest in Women's and Gender Studies Course" in "PLOS". Vol. Issue 9. DOI: 10.1371. Online.

[14] Surgenor, P. (2010). Teaching Toolkit: Learning Outcomes in UCD Teaching and Learning/Ressources. Online.

[15] Surgenor, P. (2010). Teaching Toolkit: Role of Assessment. Online.

[16] Yousefkhani, M. (2008). Impact of Instructional Objectives on e/learning Materials in "Proceedings of the World Congress on Engineering". Vol 1 Issue 2. London online.

[17] Cascio, C. (2019). Factors of Poor Student Performance retrieved May 10, 2019, from https://www.theclassroom.com/factors-poor-studentperformance-12636.html.

[18] Center for Urban Education (2017). Review Guidefor EquityMinded Practice For Equity-Minded Practice. California: University of Southern California. 